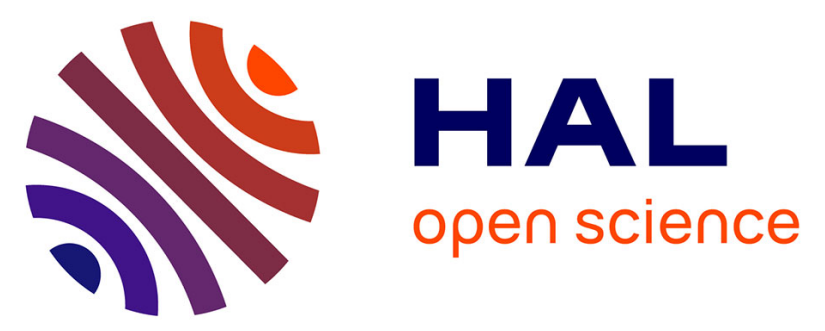

\title{
Bi-frequency-based microwave liquid sensor for multiple solutes quantification in aqueous solution
}

Thomas Chretiennot, David Dubuc, Katia Grenier

\section{To cite this version:}

Thomas Chretiennot, David Dubuc, Katia Grenier. Bi-frequency-based microwave liquid sensor for multiple solutes quantification in aqueous solution. 44th IEEE European Microwave Conference, Oct 2014, Rome, Italy. pp.287-290, 10.1109/EuMC.2014.6986426 . hal-01951713

\author{
HAL Id: hal-01951713 \\ https://hal.laas.fr/hal-01951713
}

Submitted on 9 Dec 2019

HAL is a multi-disciplinary open access archive for the deposit and dissemination of scientific research documents, whether they are published or not. The documents may come from teaching and research institutions in France or abroad, or from public or private research centers.
L'archive ouverte pluridisciplinaire HAL, est destinée au dépôt et à la diffusion de documents scientifiques de niveau recherche, publiés ou non, émanant des établissements d'enseignement et de recherche français ou étrangers, des laboratoires publics ou privés. 


\title{
Bi-frequency-based microwave liquid sensor for multiple solutes quantification in aqueous solution
}

\author{
Thomas Chretiennot ${ }^{1,2}$, David Dubuc ${ }^{1,2}$ and Katia Grenier ${ }^{1,2}$ \\ ${ }^{1}$ CNRS, LAAS, 7 avenue du colonel Roche, F-31400 Toulouse, France \\ ${ }^{2}$ Univ de Toulouse, UPS, LAAS, F-31400, Toulouse, France
}

\begin{abstract}
This paper presents a technique able to detect and quantify two different solutes in aqueous solution thanks to a single shot microwave measurements of a resonant liquid sensor at two different frequencies. The principle of operation is based on isosbestic characteristics of the sensor relatively to the two considered solutes. The solutes quantification requires a calibration phase. Extracted concentration from measurements leads to root mean square error (RMSE) of only few $\mathrm{g} / \mathrm{L}$ of solute (3.2 $\mathrm{g} / \mathrm{L}$ for glucose and $1.7 \mathrm{~g} / \mathrm{L}$ for sodium chloride). The technique then reveals the potential richness of the spectral signatures from microwave sensor for indentifying and quantifying complex liquids.
\end{abstract}

Keywords-Chemical and biological sensor, microwave, microfluidic

\section{INTRODUCTION}

Microwave sensing is one of the competitive techniques for non-destructive analysis of materials [1]. It also appears as an attracting method for chemical analysis in aqueous solution because of the enhanced water / electromagnetic-waves interaction in the microwave regime [2]-[7].

Many challenges have to be faced up in order to clearly set the applications, where microwave sensors can bring real added values compare with other techniques. Among them, the selectivity, i.e. the ability to identify components in heterogeneous liquid, represents a real challenge, as centimeter-waves average sub-centimeter constituent of the material under test. Therefore, a miniature microwave sensor able to discriminate and quantify two different solutes, which are present within a single aqueous solution, has been developed and is presented in this paper.

This paper presents in the next paragraph the sensor architecture and its microfabrication. This section also details the principle of operation as well as the conducted measurements post process. The third paragraph deals with the developed technique for the double detection of solutes in aqueous solution from one single measurement. Part IV addresses the results of the proposed technique and discusses the accuracy of extracted solute concentrations.

\section{SENSOR TECHNOLOGY, ARCHITECTURE AND OPERATION}

The sensor is based on a quarter-wavelength stub connected, on one side, to the feeding line and, on the other side, to a connected-to-ground interdigitated capacitor (IDC). The figure 1 presents a microphotograph of the microfabricated sensor integrated using a thin film microstrip technology specifically developed in the LAAS-CNRS clean room for microwave \& microfluidic sensors. Metallization are made of $0.3 \mu \mathrm{m}$-thick gold, whereas the microstrip substrate is realized by a $20 \mu \mathrm{m}$-thick SU-8 resist.

At the resonant frequency, electromagnetic simulations have demonstrated that the electromagnetic fields are mainly concentrated around the IDC, which justifies its choice as sensing zone. A microfluidic channel is then located above the IDC. It is realized using a PDMS elastomer, which has been moulded into a silicon negative replica and assembled on the microwave resonated by plasma bonding (see insert in the figure 1).

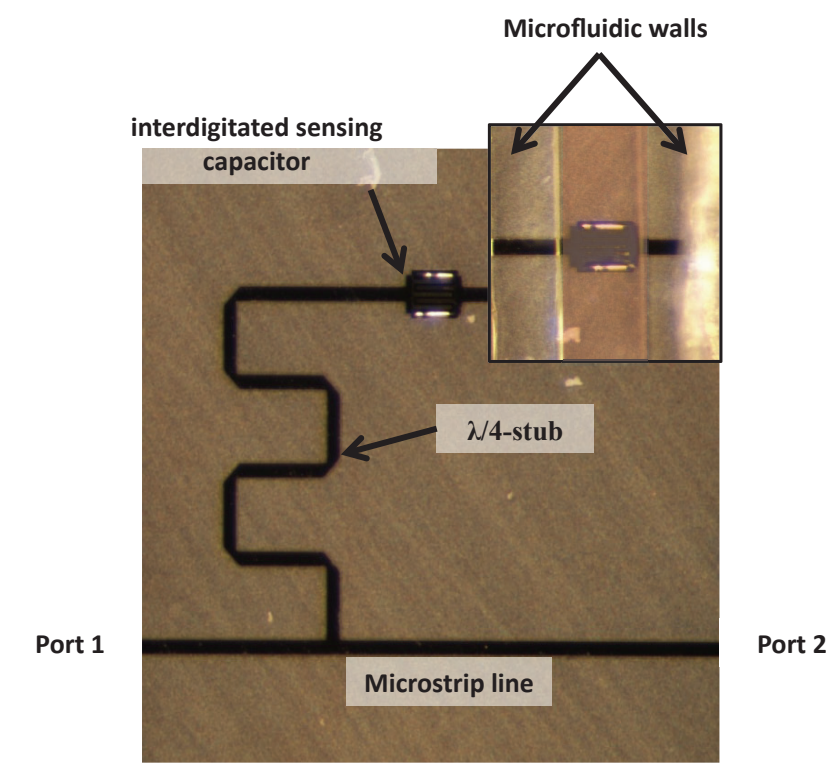

Fig. 1. Microphotograph of the microfabricated microwave stub-based sensor (insert: microfluidic channel on top of the sensing capacitor filled with a colored liquid solution)

Measurements are performed on wafer thanks to coplanar microprobes connected to a vector network analyzer, as calibration is also realized on-wafer thanks to an alumina SOLT calibration kit.

Visual inspection of microfluidic channel filling is realized before each measurement thanks to an optical microscope. Measurements are performed from $40 \mathrm{MHz}$ up to $55 \mathrm{GHz}$ and sample temperature is precisely monitored with a thermally controlled chuck. Figure 2 presents the measured $\mathrm{S}_{21}$ 
magnitude in $\mathrm{dB}$ versus frequency of the resonant based sensor after the filling of pure deionized (DI) water and glucose in aqueous solution with increasing concentrations from 5 to 80 $\mathrm{g} / \mathrm{L}$.

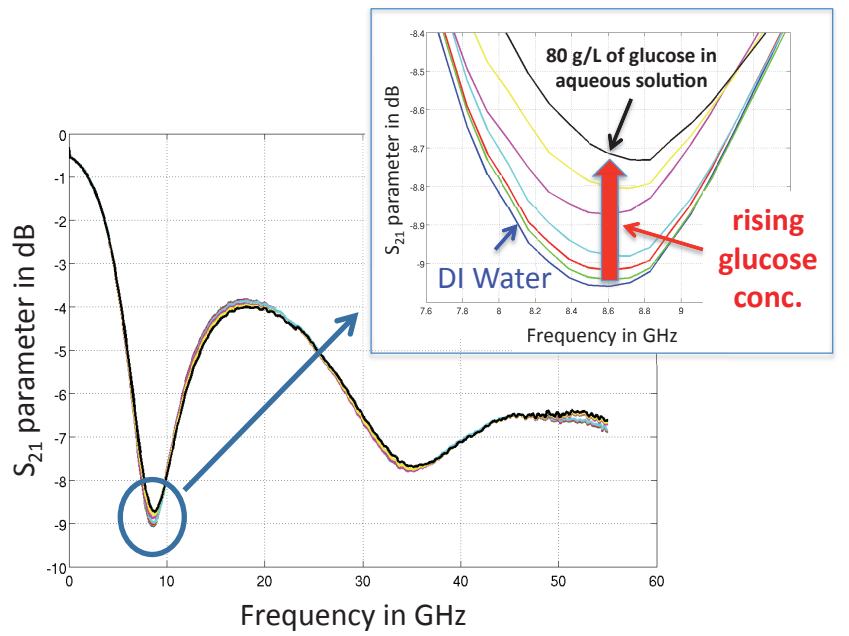

Fig. 2. Microwave response $\left(\mathrm{S}_{21}\right.$ in $\left.\mathrm{dB}\right)$ of the sensor when the microfluidic channel is filled with pure DI water and glucose in aqueous solution with increasing concentrations: 5, 10, 20, 40,60 and $80 \mathrm{~g} / \mathrm{L}$

When the aqueous solution is filling the channel, the (first) resonant frequency is around $8.4 \mathrm{GHz}$, which becomes our central frequency of interest. One can see in figure 2 the very small shift of the microwave transmission, when glucose solute is added to water and filled in the device. The insert of figure 2 presents a zoom of the measurements around the resonance of interest. Only few $0.1 \mathrm{~dB}$ of contrast separate the DI water response from the higher solute concentration solution one. In order to magnify such a contrast, we have normalized the $S_{21}$ parameter corresponding to each solute concentration ([Glucose]) with respect to the $S_{21}$ parameter when the channel is filled with DI water:

$$
\text { Normalized } \mathrm{S}_{21, \text { [Glucose] }}=\mathrm{S}_{21, \text { [Glucose }]} / \mathrm{S}_{21, \text { DI water }}
$$

This implies to follow a procedure during the measurements and for the data processing:

- We first have to inject DI water in the channel and measure the corresponding S21 parameter, which becomes the reference: $S_{21}$, DI water

- We then have to inject the liquid under test in the channel and measure the corresponding S21 parameter $\left(\mathrm{S}_{21}, \quad[\mathrm{Glucose}]\right)$ and post-process the normalization with the reference as already indicated.

The results of such normalization are presented in figure 3 . The sensor's response for DI water then corresponds to $0 \mathrm{~dB}$ and sets our reference. This figure then permits to clearly point out that:

o the contrasts are now distinguishable and clearly increasing when the glucose concentrations rises. $\circ$ the contrasts are frequency dependent according to the frequency dispersion of the liquids under test and also to the microwave response of the resonant structure.

optimal contrast frequency $\rightarrow$ maximal sensitivity

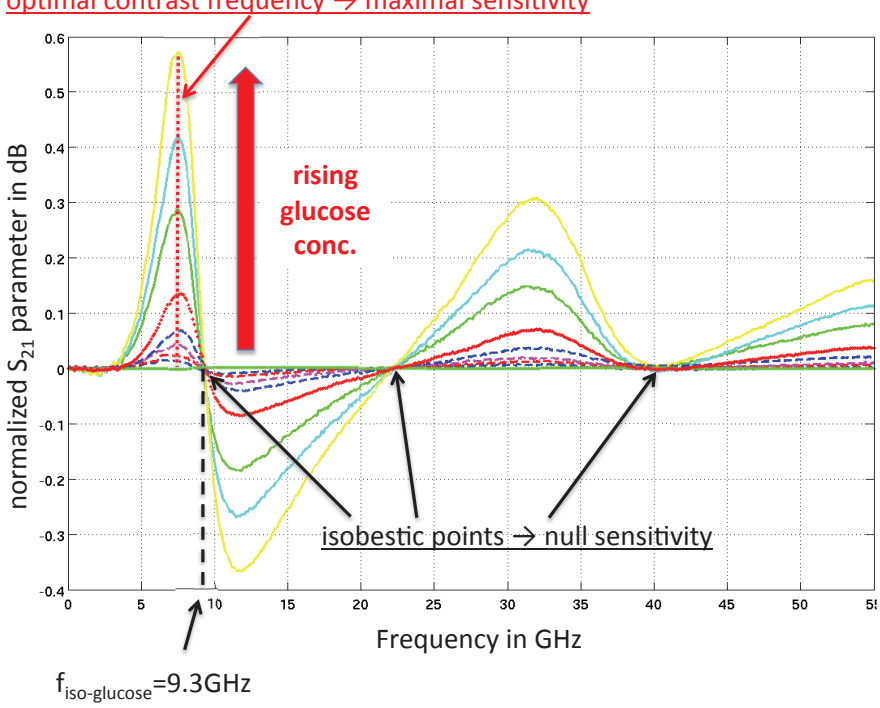

Fig. 3. Normalized microwave response $\left(\mathrm{S}_{21}\right.$ in $\left.\mathrm{dB}\right)$ of the sensor when the microfluidic channel is filled with pure DI water and glucose in aqueous solution with increasing concentrations: $1.25,2.5,5,10,20,40,60$ and $80 \mathrm{~g} / \mathrm{L}$

Figure 3 also reveals that, around the resonant frequency (8.4 $\mathrm{GHz}$ ), the sensor sensitivity to glucose concentration (and in general to solute concentration) is maximal. But the figure mainly unveils that the spectrums carry a large and rich set of information about the solute. This last remark is discussed and exploited in the next paragraph.

\section{PRINCIPLE OF THE MULTIPARAMETRIC OPERATION}

Based on the comments from the last paragraph, we compare in this paragraph the normalized $\mathrm{S}_{21}$ spectra for two solutes: glucose and sodium chloride. Our objective is to exploit the spectra characteristics to identify and quantify these two solutes, when they are mixed together in aqueous solution.

\section{A. Response for glucose in aqueous solution}

In figure 3 , is also indicated, in addition to the frequency leading to a maximum sensitivity, a set of three frequencies, for which the sensitivity is null. These frequencies refer to so called isosbestic points [8].

We consequently have some frequencies featuring high values of sensitivity and others for which the variation of glucose concentration does not impact on the transmission, response of the sensor. The first isosbestic point appears at $9.3 \mathrm{GHz}$.

In the part $\mathrm{B}$, we compare these frequencies related to glucose solute with those obtained for sodium chloride solute.

\section{B. Response for sodium chloride in aqueous solution}

Figure 4 presents the normalized (to DI water) $\mathrm{S}_{21}$ parameter in the case of $\mathrm{NaCl}$ in aqueous solution featuring various concentrations $(10,20,40,60 \mathrm{~g} / \mathrm{L})$. Around the resonant 
frequency $(8.4 \mathrm{GHz})$, the sensor sensitivity to $\mathrm{NaCl}$ concentration is maximal, as observed for glucose solution. More interesting are the four isosbestic points revealed by figure 4 .

In the case of aqueous solution of $\mathrm{NaCl}$, the first isosbestic point appears at $5.6 \mathrm{GHz}$, which is clearly different from the one obtained for glucose solution.

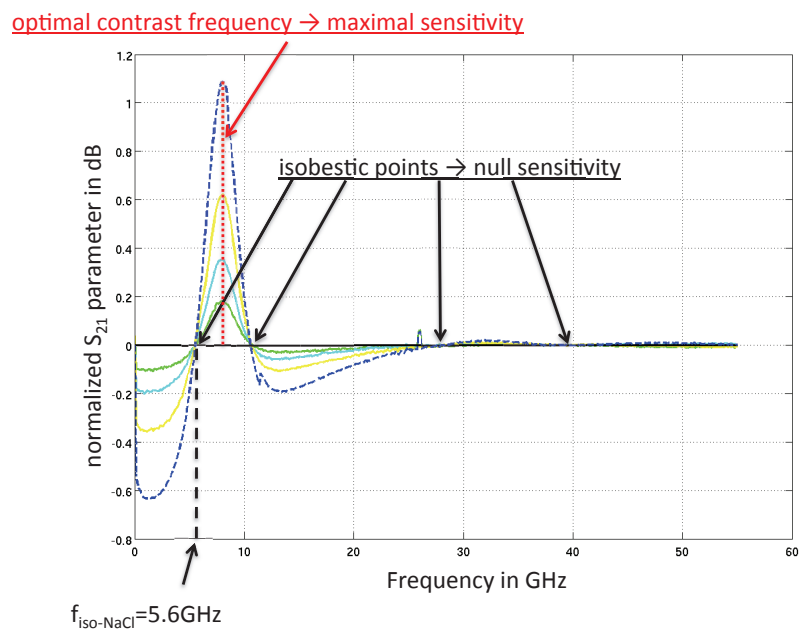

Fig. 4. Microwave response $\left(\mathrm{S}_{21}\right.$ in $\left.\mathrm{dB}\right)$ of the sensor when the microfluidic channel is filled with $\mathrm{NaCl}$ in aqueous solution featuring various concentrations.

This last remark is of importance, as it points out that the isosbestic points depend on the solute type. The next section will exploit this characteristic to propose a procedure to deduce from a solutes' mixing the concentration of each constituent from only one measurement.

\section{Procedure for multi-solute quantification}

We then have demonstrated that:

- $\quad$ at $9.3 \mathrm{GHz}$ the normalized $\mathrm{S}_{21}$ parameter only depends on the $\mathrm{NaCl}$ concentration,

- $\quad$ at $5.6 \mathrm{GHz}$ the normalized $\mathrm{S}_{21}$ parameter only depends on the Glucose concentration.

These two frequencies then permit to decorrelate the Glucose and $\mathrm{NaCl}$ impacts on the selected microwave readout and then open the capability to independently determine the concentration of these two solutes, when they are mixed together in aqueous solution.

The technique nevertheless requires three preliminary measurements for sensor calibration: with water only, with one fixed and known amount of glucose only and with one fixed and known amount of $\mathrm{NaCl}$ only. From these measurements, we determine the two frequencies and the two sensitivities (microwave readout variation vs solute concentration).

From this, we are able to determine the two solute concentrations from only one measurement of a solutes' mixture by monitoring the normalized $\mathrm{S}_{21}$ parameter at the two selected frequencies. This methodology is experimentally validated in the next paragraph.

\section{EXPERIMENTAL RESULTS}

We have followed this protocol with solutes mixtures featuring various glucose and $\mathrm{NaCl}$ concentrations as shown in the two first columns of Tables I and II.

Table I presents the exploitation of the microwave readout at 9.3 GHz, which permits to extract the sodium chloride concentration. The two first measurements are made once and serve as a sensor calibration, whereas the $\mathrm{NaCl}$ concentration is deduced directly after each following characterization. The last column of Table I presents the absolute error between the real and extracted values of concentrations.

TABLE I. SODIUM CHLORIDE QUANTIFICATION AT 9.3 GHz

\begin{tabular}{|c|c|c|c|c|}
\hline \multicolumn{2}{|c|}{$\begin{array}{c}\text { Real Concentrations } \\
(\mathrm{g} / \mathrm{L})\end{array}$} & \multirow{2}{*}{$\begin{array}{c}\mid \mathrm{S}_{21} \text { norm } \mid(\mathrm{dB}) \\
\text { at } \mathrm{f} 1=9.3 \mathrm{GHz}\end{array}$} & \multirow{2}{*}{$\begin{array}{c}\text { extracted } \\
{[\mathrm{NaCl}]} \\
(\mathrm{g} / \mathrm{L})\end{array}$} & \multirow{2}{*}{$\begin{array}{l}\text { Error } \\
\text { (g/L) }\end{array}$} \\
\hline [glucose] & [nacl] & & & \\
\hline 80 & 0 & 0 & calibration & \\
\hline 0 & 36 & 0.55 & calibration & \\
\hline 6.67 & 6 & 0.12 & 7.6 & 1.6 \\
\hline 13.33 & 12 & 0.22 & 14.0 & 2.0 \\
\hline 13.33 & 24 & 0.37 & 24.2 & 0.2 \\
\hline 26.67 & 3 & 0.05 & 3.2 & 0.2 \\
\hline 20 & 13.5 & 0.25 & 16.1 & 2.6 \\
\hline 20 & 6 & 0.12 & 7.8 & 1.8 \\
\hline 30 & 18 & 0.30 & 19.7 & 1.7 \\
\hline 15 & 27 & 0.40 & 25.8 & 1.2 \\
\hline
\end{tabular}

If we take all the measurements into account, the root mean square error (RMSE) reaches only $1.7 \mathrm{~g} / \mathrm{L}$ of $\mathrm{NaCl}$ for solutes concentration ranging from 3 to $30 \mathrm{~g} / \mathrm{L}$. Figure 5 graphically illustrates the accuracy of the sodium chloride extracted concentrations from the technique, the measurements correspond to the blue diamonds and the red line corresponds to the identity line (ideal case where extracted and real values are equal).

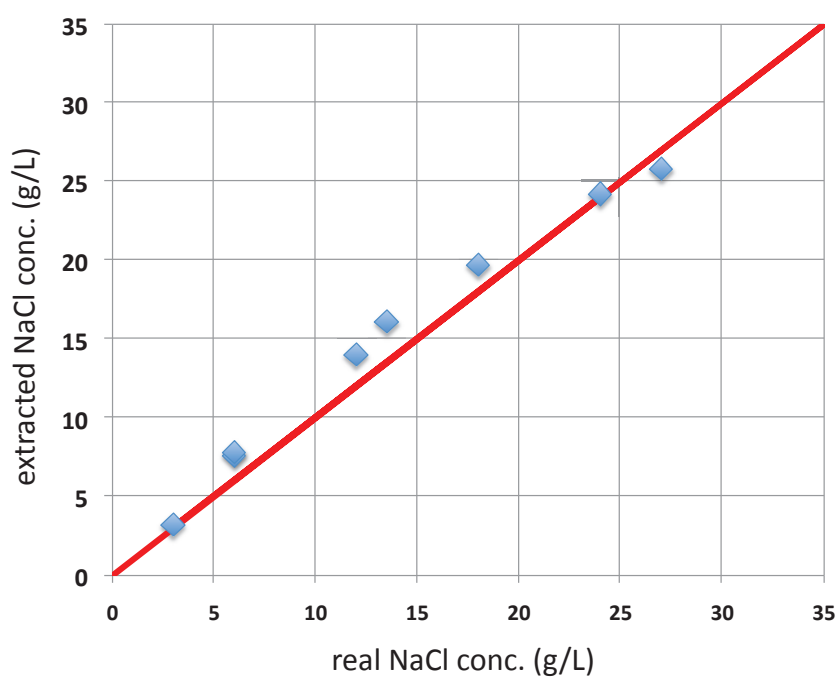

Fig. 5. Extracted vs real sodium chloride concentrations. RMSE of the extracted values $=1.7 \mathrm{~g} / \mathrm{L}$. 
Table I and figure 6 present the exploitation of the microwave readout at $5.6 \mathrm{GHz}$ for the extraction of the glucose concentration.

TABLE II. GLUCOSE QUANTIFICATION AT $5.6 \mathrm{GHz}$

\begin{tabular}{|c|c|c|c|c|}
\hline \multicolumn{2}{|c|}{$\begin{array}{c}\text { Real Concentrations } \\
(\mathrm{g} / \mathrm{L})\end{array}$} & \multirow{2}{*}{$\begin{array}{l}\mid S_{21} \text { norm } \mid(\mathrm{dB}) \\
\text { at f2=5.6 GHz }\end{array}$} & \multirow{2}{*}{$\begin{array}{c}\text { extracted } \\
\text { [glucose] } \\
\text { (g/L) }\end{array}$} & \multirow{2}{*}{$\begin{array}{l}\text { Error } \\
(\mathrm{g} / \mathrm{L})\end{array}$} \\
\hline [glucose] & [nacl] & & & \\
\hline 80 & 0 & 0.23 & calibration & \\
\hline 0 & 36 & 0 & calibration & \\
\hline 6.67 & 6 & 0.017 & 8.0 & 1,3 \\
\hline 13.33 & 12 & 0.030 & 10.5 & 2,8 \\
\hline 13.33 & 24 & 0.038 & 14.4 & 1,1 \\
\hline 26.67 & 3 & 0.089 & 33.2 & 6,5 \\
\hline 20 & 13.5 & 0.060 & 26.9 & 6,9 \\
\hline 20 & 6 & 0.050 & 19.6 & 0,4 \\
\hline 30 & 18 & 0.091 & 40.1 & 10,1 \\
\hline 15 & 27 & 0.060 & 23.9 & 8,9 \\
\hline
\end{tabular}

In this case, the RMSE reaches $3.2 \mathrm{~g} / \mathrm{L}$ but, excepted for one measurement (glucose concentration of $15 \mathrm{~g} / \mathrm{L}$ ), all the extracted glucose concentrations are within $+/-20 \%$ accuracy, which is the error tolerance of commercial glucose sensors.

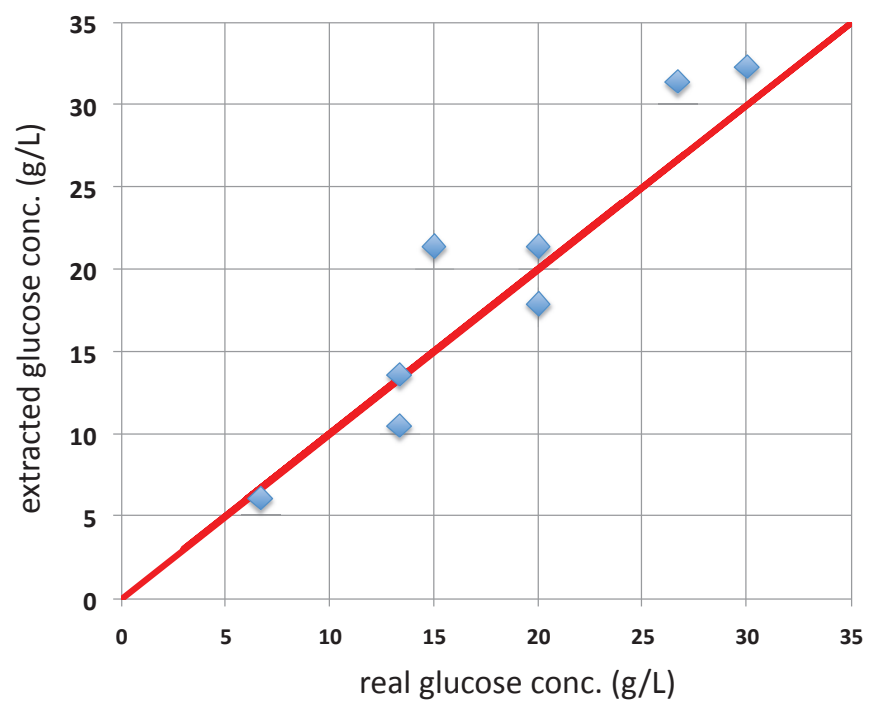

Fig. 6. Extracted vs real glucose concentrations. RMSE of the extracted values $=3.2 \mathrm{~g} / \mathrm{L}$.

\section{CONCLUSION}

This paper presents a technique able to detect and quantify two different solutes in an aqueous solution. The principle of operation is based on isosbestic characteristics of the sensor relatively to two considered solutes: glucose and sodium chloride. It is demonstrated and experimentally validated that, from the measurements at two selected frequencies, it is possible to simultaneously extract the glucose and sodium chloride concentrations of a mixture from only one measurement. The consequent root mean square error for both solutes is only around few $\mathrm{g} / \mathrm{L}$ of solute. Such results then reveal the potential richness of the spectral signatures from microwave sensor for indentifying and quantifying complex liquids.

\section{ACKNOWLEDGMENT}

The authors want to acknowledge the CNRS for its financial support as well as the RENATCH network for supporting the microfabrication of the device in the LAAS-CNRS clean room.

\section{REFERENCES}

[1] M. Schüßler, C. Mandel, M. Puentes, R. ; Jakoby, "Metamaterial Inspired Microwave Sensors", IEEE Microwave Magazine, 13 (2) pp. 57-68.

[2] National Physical Laboratory, "A guide to characterization of dielectric materials at RF and microwave frequencies", London, 2003.

[3] M. Hofmann, G. Fischer, R. Weigel, D. Kissinger, "MicrowaveBased Noninvasive Concentration Measurements for Biomedical Applications", IEEE-Trans. on MTT vol.61, no.5, pp.2195,2204, May 2013

[4] T.P. Marsland and S. Evans, "Dielectric measurements with an open-ended coaxial probe", IEEE Proceedings, vol. $34, \mathrm{n}^{\circ} 4$, pp. 341-349, 1987.

[5] B. Kapilevich and B. Litvak, "Microwave sensor for accurate measurements of water solution concentrations", Asia-Pacific Microwave Conference, 2007.

[6] G. Gennarelli, S. Romeo, M. Rosaria Scarfi and F. Soldovieri, "A microwave resonant sensor for concentration measurements of liquid solutions", IEEE Sensors Journal, vol. 13, n 5, 2013.

[7] T. H. Basey-Fisher, N. Guerra, C. Triulzi, A. Gregory, S. M. Hanham, M. M. Stevens, S. A. Maier, N. Klein, "Microwaving Blood as a Non-Destructive Technique for Haemoglobin Measurements on Microlitre Samples", Advanced Healthcare Materials, 4 sept. 2013.

[8] Fredrich Kremer and Andreas Schonhals, "Broadband Dielectric Spectrocopy", Springer 2003 